\title{
Síndrome de lisis tumoral secundario a la administración de corticoides en una adolescente sin enfermedad neoplásica confirmada: reporte de un caso
}

\author{
Tumor lysis syndrome after the administration of corticosteroids in an \\ adolescent without confirmed neoplastic disease. Case report
}

\author{
Diego Ripeau $^{a}$ (D), Mariano E. Ibarra ${ }^{b}$ (D), Rodolfo P. Moreno ${ }^{b}(\mathbb{D})$, Lucila Valentini ${ }^{b}$, Alberto Hernández ${ }^{b}$, \\ Javier Fain ${ }^{b}$, Cecilia Seligrab , Agustina Tevez Echazúb, Armando Picónc ${ }^{c}$, Gustavo Cardigni ${ }^{b}$
}

\begin{abstract}
RESUMEN
El síndrome de lisis tumoral es una complicación potencialmente letal y constituye, junto con las infecciones, la emergencia oncológica más frecuente. En pediatría, este cuadro puede ser secundario a enfermedades neoplásicas, y los corticoides son un factor desencadenante.

En este trabajo se presenta el caso de una paciente adolescente, sin neoplasias conocidas o evidentes, que desarrolló un síndrome de lisis tumoral luego de la administración de corticoides por sospecha de una infección respiratoria.

Se discute la forma de presentación y los diagnósticos diferenciales del cuadro clínico inicial. Se hace especial foco en la administración de corticoides en cuadros clínicos en los que no existe evidencia científica que respalde fuertemente su indicación. El uso de corticosteroides sistémicos en infecciones respiratorias agudas debe ser evaluado en el contexto clínico y solo debe indicarse en situaciones con probada efectividad. Palabras clave: sindrome de lisis tumoral, corticosteroides, niño, pediatría.
\end{abstract}

\section{ABSTRACT}

Tumor lysis syndrome is a potentially lethal complication and constitutes with infections the most frequent oncological emergency. In children, this condition can be secondary to neoplastic diseases, with corticosteroids being a triggering factor.

This paper presents the case of an adolescent patient, without known or obvious neoplasms, who developed a tumor lysis syndrome after the administration of corticosteroids due to suspected respiratory infection.

a. Servicio de Nefrología Pediátrica.

b. Servicio de Pediatría.

c. Servicio de Oncología Pediátrica.

Sanatorio de la Trinidad Palermo, Ciudad Autónoma de

Buenos Aires, Argentina.

\section{Correspondencia:}

Diego Ripeau: diegoripeau@gmail.com

Financiamiento: Ninguno.

Conflicto de intereses: Ninguno que declarar.

Recibido: 9-6-2021

Aceptado: 3-8-2021
The clinical presentation and differential diagnoses are discussed. Special focus is placed on the administration of corticosteroids in clinical conditions with weak scientific evidence. The use of systemic corticosteroids in acute respiratory infections should be evaluated in the clinical context and only indicated in situations with proven effectiveness.

Key words: tumor lysis syndrome, corticosteroids, child, pediatrics.

http: / / dx.doi.org/10.5546/ aap.2022.e49

Cómo citar: Ripeau D, Ibarra ME, Moreno RP, Valentini L, et al. Síndrome de lisis tumoral secundario a la administración de corticoides en una adolescente sin enfermedad neoplásica confirmada: reporte de un caso. Arch Argent Pediatr 2022;120(1):e49-e53.

\section{INTRODUCCIÓN}

El síndrome de lisis tumoral (SLT) es una complicación potencialmente letal provocada por la liberación masiva de ácidos nucleicos, potasio y fosfato hacia la circulación, ${ }^{1}$ resultado de la lisis de células neoplásicas, frecuentemente hematológicas. ${ }^{2}$ Los corticoides son un factor desencadenante para $\mathrm{SLT}^{3,4} \mathrm{y}$, además, suelen utilizarse en infecciones respiratorias sin justificación clara. ${ }^{5}$ Se debe realizar una evaluación integral de los pacientes durante la consulta clínica y realizar indicaciones adecuadas de medicamentos. En este reporte describimos la evolución tórpida de una paciente con SLT secundaria a la administración de corticoides.

\section{CASO CLÍNICO}

Adolescente de 14 años, previamente sana, que presentaba disnea y tos seca 20 días antes de la internación. Se interpretó el cuadro como infección respiratoria y recibió claritromicina durante 10 días. Evolucionó afebril, con dolor abdominal, vómitos y odinofagia, por lo cual consultó en el Servicio de Emergencias de otra institución. Le indicaron penicilina y dexametasona por vía intramuscular durante 2 días consecutivos. Por persistir los síntomas, 
volvió a consultar en dicho centro médico, y le realizaron laboratorio: glóbulos blancos 14500 / $\mathrm{mm}^{3}$, hematocrito $34 \%$, hemoglobina $11,5 \mathrm{~g} / \mathrm{dl}$, plaquetas $318000 / \mathrm{mm}^{3}$, urea $175 \mathrm{mg} / \mathrm{dl}$, creatinina 2,52 mg/ dl, amilasa $539 \mathrm{mg} / \mathrm{dl}$, hepatograma normal y orina completa con hemoglobinuria $(+)$. Se la derivó a nuestra institución por sospecha de pancreatitis aguda con insuficiencia renal.

La paciente ingresó en regular estado general, ligera palidez cutánea, mucosas secas. Hemodinámicamente compensada. Disneica, taquipneica con hipoventilación marcada en campo pulmonar izquierdo, sin hipoxemia. Sin adenomegalias ni visceromegalias. Abdomen normal. Fauces y resto del examen físico normal. Se realizó radiografía de tórax y se constató derrame pleural izquierdo y ensanchamiento mediastinal. La tomografía de tórax confirmó el derrame pleural y mostró una formación hipodensa en mediastino (Figura 1). La paciente presentó insuficiencia renal (urea $211 \mathrm{mg} / \mathrm{dl}$, creatinina $4,45 \mathrm{mg} / \mathrm{dl}$ ) y acidosis metabólica con anión restante aumentado. En el Tabla 1 se muestran todos los valores de laboratorio. Con sospecha de SLT, se indicó rasburicase y comenzó con hemodiálisis diaria durante 48 horas. Frente a la presunción de SLT secundario a neoplasia oncohematológica, se realizó punción aspiración de médula ósea, citología y anatomía patológica de líquido pleural. Debido a que las muestras tomadas arrojaron resultados inespecíficos, se decidió realizar biopsia de masa mediastínica con anatomía patológica y citometría compatibles con inflamación inespecífica, sin signos de proceso neoplásico.

Evolucionó con mejoría de los parámetros de laboratorio y resolución de la insuficiencia renal, disminución franca de la masa mediastínica y sin nueva colección de líquido pleural, por lo que se otorgó el egreso con seguimiento ambulatorio, sin diagnóstico etiológico ni tratamiento a los 22 días del ingreso.

A los 2 meses de seguimiento, aparecieron blastos en sangre periférica y reapareció la masa mediastínica. Se internó y se realizó el diagnóstico de leucemia linfoblástica aguda (LLA) T. Se inició tratamiento de inducción con medidas de prevención, sin desarrollar nuevo SLT.

\section{DISCUSIÓN}

El SLT constituye, junto con las infecciones, la emergencia oncológica más frecuente. El riesgo para desarrollar SLT depende del tipo de neoplasia, el tratamiento antitumoral, las medidas de profilaxis y las características del paciente. Es más frecuente al inicio del tratamiento de enfermedades oncohematológicas agudas con grandes masas tumorales y/o con alto índice proliferativo, como la leucemia linfoblástica aguda y el linfoma de Burkitt. ${ }^{1,2}$

Si bien los fármacos que habitualmente desencadenan SLT son los quimioterápicos citotóxicos, existen reportes de SLT espontáneo, asociado a radioterapia, talidomida, fármacos biológicos (rituximab o bortezomib) o corticoides, como probablemente ocurrió en este caso.

FIgura 1. Diagnóstico por imágenes al ingreso. A: se observa opacidad del hemitórax izquierdo compatible con derrame pleural en la radiografía de tórax frente. $\boldsymbol{B}$ y $\boldsymbol{C}$ : en la tomografía computada de tórax, se observa formación hipodensa con densidad de partes blandas que envuelve estructuras vasculares del mediastino

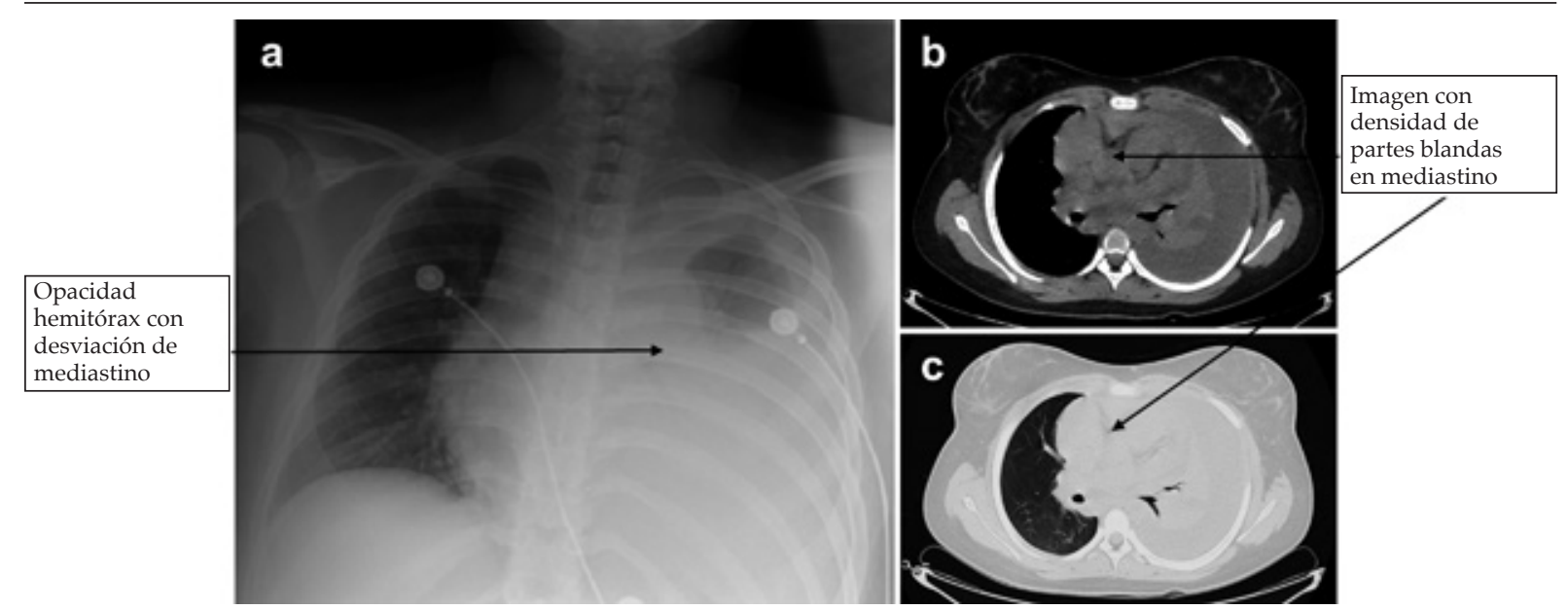


En pediatría, los corticoides se han utilizado durante más de 60 años en el tratamiento de la LLA. Inducen una remisión inicial en el $60 \%$ de los niños, pero esta remisión es transitoria y rara vez supera los 4 meses. Fuera de las enfermedades oncológicas, los corticoides se indican en una miríada de enfermedades agudas o crónicas, y sus efectos secundarios son proporcionales a la duración y a la dosis prescripta. ${ }^{5}$ En pediatría es frecuente su uso fuera de las recomendaciones. En este sentido, es necesario revisar las indicaciones de uso de corticosteroides sistémicos para las infecciones respiratorias agudas (IRA) y los problemas de seguridad asociados. ${ }^{6}$ Los pediatras deben conocer los efectos adversos poco frecuentes, ${ }^{7}$ pero potencialmente graves. ${ }^{8}$
Dentro de los factores de riesgo para desarrollar SLT relacionados con el paciente, la enfermedad renal preexistente, el estado de hidratación y el uso concomitante de fármacos nefrotóxicos son los más destacados. ${ }^{9}$ En el caso en cuestión, si bien no existen datos sobre la función renal previa, la buena evolución posterior descarta el compromiso renal preexistente. Seguramente, el uso de analgésicos y el estado de deshidratación secundaria a vómitos predispusieron a una situación de riesgo aumentado para SLT.

Si bien al momento de la internación la paciente reunía criterios clínicos (lesión renal aguda con aumento de la creatinina) y de laboratorio (hiperuricemia, hiperfosfatemia

TABLA 1. Resultados de los estudios complementarios

\begin{tabular}{|c|c|c|c|c|}
\hline & Día 1 & Día 2 & Día 3 & Día 4 \\
\hline \multicolumn{5}{|l|}{ Tratamiento } \\
\hline Rasburicase & & $X$ & & \\
\hline Hemodiálisis & & $X$ & $\mathrm{X}$ & \\
\hline \multicolumn{5}{|l|}{ Hemograma } \\
\hline Glóbulos blancos $\left(/ \mathrm{mm}^{3}\right)$ & 11900 & 8100 & 6700 & 5200 \\
\hline Hematocrito $(\%)$ & 33,8 & 31,9 & 29,3 & 30,5 \\
\hline Plaquetas $\left(/ \mathrm{mm}^{3}\right)$ & 312000 & 281000 & 278000 & 249000 \\
\hline \multicolumn{5}{|l|}{ Función renal } \\
\hline Urea $(\mathrm{mg} / \mathrm{dl})$ & 203 & 211 & 157 & 109 \\
\hline Creatinina (mg/dl) & 3,7 & 4,25 & 4,45 & 3,94 \\
\hline $\mathrm{pH} / \mathrm{pCO}_{2} / \mathrm{HCO}_{3}^{-}$(unidades $\mathrm{pH}, \mathrm{mmHg}, \mathrm{mg} / \mathrm{dl}$ ) & $7,23 / 29 / 12$ & $7,18 / 41 / 15$ & $7,27 / 43 / 19$ & $7,28 / 48 / 22$ \\
\hline \multicolumn{5}{|l|}{ Parámetros SLT } \\
\hline $\mathrm{Na} / \mathrm{K} / \mathrm{Cl}(\mathrm{mEq} / \mathrm{l})$ & $138 / 4,7 / 101$ & $144 / 4,7 / 104$ & $142 / 4,4 / 104$ & $138 / 4 / 102$ \\
\hline Ác. úrico (mg/dl) & 38,6 & 36 & 0,6 & $<0,1$ \\
\hline $\mathrm{Ca} / \mathrm{P} / \mathrm{Mg}(\mathrm{mg} / \mathrm{dl})$ & $5,6 / 16,3 / 12,2$ & $6,9 / 16,4 / 3,1$ & $6,9 / 9,4 / 2,6$ & $7,4 / 6,5 / 2,3$ \\
\hline LDH (UI/1) & 371 & 1947 & 2055 & 1449 \\
\hline \multicolumn{5}{|l|}{ Otros } \\
\hline Amilasa/Lipasa (mg/dl) & $254 / 239$ & & & $65 / 42$ \\
\hline Proteínas / Albúmina (g/dl) & $7,2 / 3,7$ & & $-/ 2,6$ & $-/ 2,6$ \\
\hline \multicolumn{5}{|l|}{ Otros estudios realizados durante la internación } \\
\hline Líquido pleural & $\begin{array}{l}\text { Leucocitos } 1670 / \mathrm{mm}^{3} \text { (6 } \\
\text { Glucosa } 114 \mathrm{mg} / \mathrm{dl} \\
\text { LDH } 11083 \mathrm{UI} / \mathrm{L} \\
\text { Proteínas } 3,5 \mathrm{~g} / \mathrm{dl} \\
\text { Albúmina } 2,19 \mathrm{~g} / \mathrm{dl} \\
\text { Amilasa } 35 \mathrm{UI} / 1\end{array}$ & polimorfonuc & & \\
\hline PCR para COVID-19 & \multicolumn{4}{|l|}{ Negativo } \\
\hline Perfil reumatológico & \multicolumn{4}{|c|}{ C3, C4, FAN, anti-ADN y ANCA normales } \\
\hline Serologías & \multicolumn{4}{|c|}{$\begin{array}{l}\text { EBV, CMV, parvovirus B19, toxoplasmosis, Chagas, VDRL, VHA, VHB y } \\
\text { VHC negativas }\end{array}$} \\
\hline
\end{tabular}

$\mathrm{pCO}_{2}$ : presión de dióxido de carbono; $\mathrm{HCO}_{3}^{-}$: bicarbonato; $\mathrm{Na}$ : sodio; $\mathrm{K}$ : potasio; Cl: cloro; Ca: calcio; P: fósforo; Mg: magnesio; LDH: lactato deshidrogenasa; COVID-19: enfermedad por el nuevo coronavirus; C3 y C4: factores del complemento 3 y 4; FAN: factores antinucelares; anti-DNA: anticuerpos anti-ADN; ANCA: anticuerpos anticitoplasma de neutrófilos; EBV: virus de Epstein-Barr; CMV: citomegalovirus; VDRL: prueba de laboratorio de investigación de enfermedades venéreas; VHA: virus de la hepatitis A; VHB: virus de la hepatitis B; VHC: virus de la hepatitis C. 
e hipocalcemia) de SLT, acorde a los criterios de Cairo y Bishop, ${ }^{10}$ no se pudo confirmar el diagnóstico de una enfermedad oncológica desencadenante. Aun así, los valores elevados de ácido úrico y de fósforo, no habituales en otras causas de lesión renal aguda, hicieron sospechar una causa primaria de generación de estos por sobre la simple acumulación secundaria a la caída del filtrado y reforzaron la sospecha de SLT. Al no detectar enfermedad maligna evidente, entre los diagnósticos diferenciales se deben considerar enfermedades no malignas, que puedan tener una presentación clínica y de laboratorio similar al SLT (denominado símil SLT), como leishmaniosis visceral, enfermedad de Castleman, histiocitosis de células de Langerhans, hemangioma infantil, mielopoyesis anormal transitoria y mielodisplasia. ${ }^{11}$ Todas estas patologías fueron descartadas en la paciente descripta.

En cuanto al tratamiento, una vez establecido el SLT, los esfuerzos deben enfocarse en restablecer las concentraciones normales de los solutos extracelulares. Para ello, se indican la hidratación adecuada (con el objetivo de aumentar la excreción de potasio, fósforo y ácido úrico, aumentar el flujo urinario y disminuir el producto fosfocálcico dentro de los túbulos renales), el uso de quelantes de fósforo, la utilización de enzima recombinante urato oxidasa y las técnicas de reemplazo renal., 3,9,10

Durante la segunda internación, se confirmó el diagnóstico oncológico. Con la paciente normohidratada y las medidas de prevención adecuadas, se inició el tratamiento de inducción para LLA sin desarrollo de SLT. Este hecho pone en evidencia la importancia de las medidas de prevención para SLT. 2,12 Dado que el SLT agudo es una emergencia médica con una alta tasa de mortalidad, el reconocimiento y la prevención, especialmente en los pacientes con alto riesgo de SLT, es esencial.

Aunque los esteroides se utilizan ampliamente, solo hay reportes aislados de pacientes tratados solo con corticoides que desarrollaron SLT, ${ }^{4}$ aunque este puede ser grave. ${ }^{9}$ Además, los corticoides pueden ser causa de retraso en el diagnóstico e instauración del tratamiento en enfermedades oncológicas, y pueden aumentar las complicaciones infecciosas iniciales. ${ }^{13}$

La decisión de utilizar cualquier tratamiento implica evaluar riesgos y beneficios. Los corticoides sistémicos como tratamiento de la insuficiencia renal aguda carecen de evidencia fuerte, sin embargo, su uso continúa en aumento. ${ }^{5}$
El tratamiento indicado en otra institución con antibióticos y corticoides por un cuadro de disnea y tos de 20 días de evolución debe llamarnos a la reflexión a los pediatras. Las IRA se encuentran entre las enfermedades agudas más comunes en pediatría. Suelen prescribirse antibióticos sabiendo que la mayoría de ellas tiene etiología viral, y corticoides sistémicos desconociendo su eficacia en el tratamiento de las IRA. Ambas medicaciones tienen efectos secundarios, algunos potencialmente graves, y pueden ocasionar dificultades en llegar a los diagnósticos etiológicos, como en la paciente que se presenta aquí. En un estudio de cohorte realizado en más de 4 millones de niños, el $42 \%$ estuvo expuesto a corticosteroides en el período de estudio de 5 años. ${ }^{8}$ Los corticoides se prescribieron para niños con IRA $(34 \%)$ y enfermedades alérgicas (31\%). La administración de corticoides se asoció significativamente con hemorragia gastrointestinal, sepsis y neumonía, durante el primer mes después del inicio de la terapia con corticoides. Respecto al uso de corticoides como tratamiento de la odinofagia, una revisión de Cochrane mostró que la evidencia es contradictoria. Los autores concluyeron que se necesitan más investigaciones sobre los daños y beneficios de los cursos cortos y los ciclos cortos múltiples de corticoides para permitir una toma de decisiones informada. ${ }^{14}$

Debemos mejorar la práctica médica, priorizando la evaluación clínica, y evaluar las indicaciones, contraindicaciones y efectos adversos de cada medicación que se prescribe. Para ello, los programas de educación médica deben incluir contenidos acerca de los riesgos potenciales y los beneficios limitados de la prescripción de esteroides en el contexto de las IRA, que reflejen fielmente la totalidad de la evidencia existente.

Para finalizar, la indicación de tratamiento con corticoides en pediatría debe ser precisa y se deben considerar los riesgos, que, aunque improbables, pueden ser graves. La administración inadecuada de corticoides imposibilitó llegar al diagnóstico etiológico en la primera internación, lo que retrasó el comienzo de la terapéutica. Es necesario realizar mayor difusión de las complicaciones a fin de evitar la presentación de nuevos casos.

\section{REFERENCIAS}

1. Rahmani B, Patel S, Seyam O, Gandhi J, et al. Current understanding of tumor lysis syndrome. Hematol Oncol. 2019; 37(5):537-47. 
2. Criscuolo M, Fianchi L, Dragonetti G, Pagano L. Tumor lysis syndrome: review of pathogenesis, risk factors and management of a medical emergency. Expert Rev Hematol. 2016; 9(2):197-208.

3. Wesemüller W, Taverna C. Spontaneous Tumor Lysis Syndrome. Case Rep Oncol. 2020; 13(3):1116-24.

4. Tiley C, Grimwade D, Findlay M, Treleaven J, et al. Tumour lysis following hydrocortisone prior to a blood product transfusion in T-cell acute lymphoblastic leukaemia. Leuk Lymphoma. 1992; 8(1-2):143-6.

5. Lin K, Dvorin E, Kesselheim A. Prescribing systemic steroids for acute respiratory tract infections in United States outpatient settings: A nationwide population-based cohort study. PLoS Med. 2020; 17(3):e1003058.

6. Dvorin E, Lamb M, Monlezun D, Boese A, et al. High Frequency of Systemic Corticosteroid Use for Acute Respiratory Tract Illnesses in Ambulatory Settings. JAMA Intern Med. 2018; 178(6):852-4.

7. Sadeghirad B, Siemieniuk R, Brignardello-Petersen R, Papola D, et al. Corticosteroids for treatment of sore throat: systematic review and meta-analysis of randomised trials. BMJ. 2017; 358:j3887.

8. Yao T, Wang J, Chang S, Chang Y, et al. Association of Oral Corticosteroid Bursts With Severe Adverse Events in Children. JAMA Pediatr. 2021; 175(7):723-9.

9. Xue Y, Chen J, Gao S, Zhai X, et al. Clinical characteristics of tumor lysis syndrome in childhood acute lymphoblastic leukemia. Sci Rep. 2021; 11(1):9656.

10. Cairo M, Bishop M. Tumour lysis syndrome: new therapeutic strategies and classification. $\mathrm{Br} J$ Haematol. 2004; 127(1):3-11.

11. Urae S, Tsuruoka K, Kuroya S, Shibagaki Y. Tumor Lysislike Syndrome in Eosinophilic Disease of the Lung: A Case Report and Review of the Literature. Intern Med. 2016; 55(20):3029-34

12. Matuszkiewicz-Rowinska J, Malyszko J. Prevention and Treatment of Tumor Lysis Syndrome in the Era of OncoNephrology Progress. Kidney Blood Press Res. 2020;45(5):64560.

13. Gatineau-Sailliant S, Buchbinder N, Callat M, Nelken N, et al. Corticothérapie préalable au diagnostic de leucémie aiguë lymphoblastique (LAL) de l'enfant: effet délétère pour la prise en charge diagnostique et thérapeutique. Arch Pediatr. 2013; 20(4):341-7.

14. de Cassan S, Thompson MJ, Perera R, Glasziou PP, et al. Corticosteroids as standalone or add-on treatment for sore throat. Cochrane Database Syst Rev. 2020; 5(5):CD008268. 